\title{
Nitrogen-doped graphene films from chemical vapor deposition of pyridine: influence of process parameters on the electrical and optical properties
}

\author{
Andrea Capasso ${ }^{* 1,2}$, Theodoros Dikonimos ${ }^{1}$, Francesca Sarto ${ }^{3}$, Alessio Tamburrano ${ }^{4}$, \\ Giovanni De Bellis ${ }^{4}$, Maria Sabrina Sarto ${ }^{4}$, Giuliana Faggio ${ }^{5}$, Angela Malara ${ }^{5}$, \\ Giacomo Messina ${ }^{5}$ and Nicola Lisi ${ }^{1}$
}

\section{Full Research Paper}

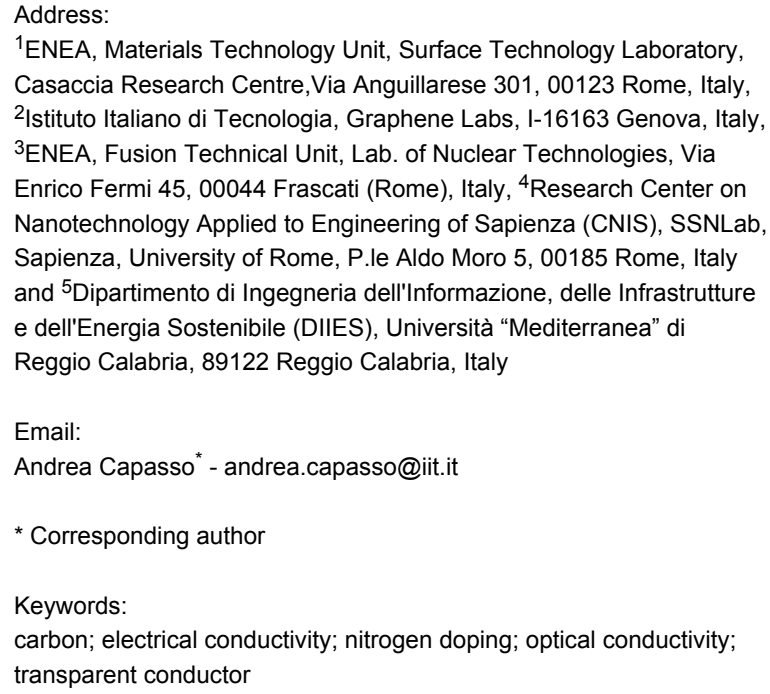

${ }^{1} E N E A$, Materials Technology Unit, Surface Technology Laboratory, Casaccia Research Centre,Via Anguillarese 301, 00123 Rome, Italy, 2Istituto Italiano di Tecnologia, Graphene Labs, I-16163 Genova, Italy, ${ }^{3}$ ENEA, Fusion Technical Unit, Lab. of Nuclear Technologies, Via Enrico Fermi 45, 00044 Frascati (Rome), Italy, ${ }^{4}$ Research Center on Nanotechnology Applied to Engineering of Sapienza (CNIS), SSNLab, Sapienza, University of Rome, P.le Aldo Moro 5, 00185 Rome, Italy and ${ }^{5}$ Dipartimento di Ingegneria dell'Informazione, delle Infrastrutture e dell'Energia Sostenibile (DIIES), Università "Mediterranea" di Reggio Calabria, 89122 Reggio Calabria, Italy

Email:

Andrea Capasso* - andrea.capasso@iit.it

${ }^{*}$ Corresponding author

\section{Keywords:}

carbon; electrical conductivity; nitrogen doping; optical conductivity; transparent conductor

\author{
Beilstein J. Nanotechnol. 2015, 6, 2028-2038. \\ doi:10.3762/bjnano.6.206 \\ Received: 08 July 2015 \\ Accepted: 22 September 2015 \\ Published: 14 October 2015 \\ Associate Editor: J. Lau \\ (c) 2015 Capasso et al; licensee Beilstein-Institut. \\ License and terms: see end of document.
}

\begin{abstract}
Graphene films were produced by chemical vapor deposition (CVD) of pyridine on copper substrates. Pyridine-CVD is expected to lead to doped graphene by the insertion of nitrogen atoms in the growing $\mathrm{sp}^{2}$ carbon lattice, possibly improving the properties of graphene as a transparent conductive film. We here report on the influence that the CVD parameters (i.e., temperature and gas flow) have on the morphology, transmittance, and electrical conductivity of the graphene films grown with pyridine. A temperature range between 930 and $1070{ }^{\circ} \mathrm{C}$ was explored and the results were compared to those of pristine graphene grown by ethanol-CVD under the same process conditions. The films were characterized by atomic force microscopy, Raman and X-ray photoemission spectroscopy. The optical transmittance and electrical conductivity of the films were measured to evaluate their performance as transparent conductive electrodes. Graphene films grown by pyridine reached an electrical conductivity of $14.3 \times 10^{5} \mathrm{~S} / \mathrm{m}$. Such a high conductivity seems to be associated with the electronic doping induced by substitutional nitrogen atoms. In particular, at $930{ }^{\circ} \mathrm{C}$ the nitrogen/carbon ratio of pyridine-grown graphene reaches $3 \%$, and its electrical conductivity is $40 \%$ higher than that of pristine graphene grown from ethanol-CVD.
\end{abstract}




\section{Introduction}

Transparent conductive electrodes (TCEs) are an indispensable component of many kinds of electronic devices, such as displays, touch-screens, light emitting diodes, and solar cells [1-8]. Since its discovery, graphene was proposed as an ideal material for TCEs thanks to its transparency and superior electrical conductivity $[9,10]$. To date, graphene films have been produced through a multitude of different techniques and used to fabricate devices. However, the achieved electronic characteristics still need further improvement for a fruitful application in consumer electronics [11,12]. Although the highest electron mobility is usually reached in mechanically exfoliated graphene crystals [13], the most suitable route for the production of highquality graphene for electronics is probably chemical vapor deposition (CVD). By this technique it is possible to produce graphene with large grain sizes and high crystalline quality over large areas [14]. Nonetheless, the sheet resistance of most CVD-graphene films (even in single-crystal form) still falls short of the requirements for TCEs [14-16].

The impact that graphene will have on many fields of electronics ultimately depends on the real properties it will be able to provide. Thus, doping of graphene is currently considered a promising way of enhancing its carrier density and improving the electrical conductivity to satisfy the requirements of various electronic applications [16]. Nevertheless, the product of electron mobility and dopant concentration generally remains constant, and thus there is a limit to the achievable improvement in electrical conductivity by this approach [17]. Besides, the electron mobility itself can be greatly affected by the presence of substitutional atoms (which are a kind of lattice defects, such as vacancies, and grain boundaries) [18].

Graphene can be doped through surface proximity by layering it with other materials (such as metals [19], polymers [20], atoms [21] and molecular functional groups [22]) that alter its electronic properties and can also, in principle, open a bandgap, giving graphene semiconductor properties. In an alternative way, graphene can be doped by substitution, i.e., by inserting heterogeneous atoms into the lattice. When using CVD, the choice of a carbon-based precursor containing specific atoms or groups can give rise to direct, single-step growth of doped graphene. In contrast to proximity doping, substitutional doping modifies the crystal lattice of graphene but generally preserves the chemical inertness of the material.

Due to its size, nitrogen is one of the few atoms (along with boron) that can fit within the graphene lattice [23]. When bound to carbon atoms sharing four valence electrons, nitrogen should ideally confer n-type doping to graphene due to the availability of an extra electron. Doping with nitrogen might also confer useful chemical properties to graphene, e.g., rendering it catalytic to oxygen reduction reactions [24] or enhancing its lithium intercalation properties for battery applications [25]. Nitrogen doping was originally achieved ex situ by the postgrowth treatment of pristine CVD graphene in ammonia gas [26]. However, few attempts have been made of directly growing nitrogen-doped graphene onto metal foils by CVD using N-containing precursors. On platinum surfaces, nitrogendoped carbon films were grown below $500{ }^{\circ} \mathrm{C}$ with acetonitrile and below $700{ }^{\circ} \mathrm{C}$ with pyridine [27,28]. On copper foils, nitrogen-doped graphene was grown with dimethylformamide vapor at $950{ }^{\circ} \mathrm{C}[29]$.

In this paper, we grew graphene films by CVD of pyridine on copper surfaces, evaluating the occurrence of doping by substitutional nitrogen atoms in the films. Several groups recently started to produce graphene using liquid carbon precursors such as ethanol (instead of hydrocarbon gases, such as methane) because of their effectiveness, safety and low-cost. Pyridine $\left(\mathrm{C}_{5} \mathrm{H}_{5} \mathrm{~N}\right)$ is a liquid precursor akin to ethanol $\left(\mathrm{C}_{2} \mathrm{H}_{5} \mathrm{OH}\right)$. The main difference between the two is that ethanol is generally used to make pristine graphene while pyridine can be used to form nitrogen-doped graphene. Our group recently showed that highly-crystalline, pristine graphene can be produced by ethanol-CVD on copper above $1000{ }^{\circ} \mathrm{C}$ [30,31]. However, it has been reported that below $900{ }^{\circ} \mathrm{C}$ the graphene films grown by ethanol-CVD showed some evidence of oxidation [32]. Ethanol is known to decompose during CVD into oxygen-carrying and hydrocarbon molecules or radicals: Below a certain temperature, some of the oxygen atoms or groups might bind to defects, grains or edges [33]. Likewise, in the case of pyridine-CVD, the temperature can have a profound effect on the insertion of nitrogen atoms into the graphene lattice (and hence on the doping level). Pyridine decomposes mainly into hydrogen, acetylene $\left(\mathrm{C}_{2} \mathrm{H}_{2}\right)$ and hydrogen cyanide (HCN) [34], which is the compound expected to be at the basis of the heterogeneous doping of graphene. The dissociation of $\mathrm{HCN}$ and the interaction of the dissociated species with the copper surface (and with the forming graphene clusters) can be strongly influenced by the CVD parameters (i.e., temperature and vapor composition). The growth of nitrogen-doped graphene by CVD of pyridine was recently demonstrated at $1000{ }^{\circ} \mathrm{C}$ [35]. To date however, there are no systematical studies on the effect of temperature and hydrogen flow in pyridine-CVD. Therefore, we here explored a wide range of CVD process parameters $\left(930-1070{ }^{\circ} \mathrm{C}\right.$ for temperatures, 0-100 sccm for $\mathrm{H}_{2}$ flow in the vapor mixture) to assess their effect on the graphene properties. In order to better evaluate such effect and assess the occurrence of nitrogen doping, we further run a systematic comparison with the 
graphene films made by ethanol-CVD under analogous conditions [30].

\section{Results and Discussion Spectroscopic analyses of the graphene samples}

The graphene films grown by pyridine for $10 \mathrm{~min}$ at different temperatures $\left(930{ }^{\circ} \mathrm{C}, 1000{ }^{\circ} \mathrm{C}\right.$ and $\left.1070{ }^{\circ} \mathrm{C}\right)$ with two different hydrogen flows (1 and $100 \mathrm{sccm}$ ) were transferred on $\mathrm{Si} / \mathrm{SiO}_{2}$ $(300 \mathrm{~nm})$ and analyzed by micro-Raman spectroscopy. At the optical microscope, the graphene films showed the typical features of those grown by other carbon precursors (such as methane and ethanol) on commercial copper foils. They are overall uniform and have some darker areas running along parallel stripes, which are graphene grains developed at sites of secondary nucleation induced by the lamination process undergone by the copper foil [36,37].
Figure 1 shows the spectra of graphene films grown by CVD of pyridine at different temperatures and with two hydrogen flows. The spectra of graphene films grown by CVD of ethanol (10 min, with 1 and $100 \mathrm{sccm}$ of hydrogen) are also reported for comparison. The results of the peak fitting (peak features and

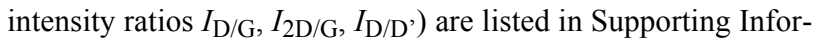
mation File 1 (Table S1 and Table S2).

In all the Raman spectra, the typical $G$ and $2 D$ peaks of graphene (centered at $\approx 1585 \mathrm{~cm}^{-1}$ and $\approx 2700 \mathrm{~cm}^{-1}$, respectively) are present. The $\mathrm{D}$ and $\mathrm{D}^{\prime}$ peaks $\left(\approx 1350 \mathrm{~cm}^{-1}\right.$ and $\approx 1620 \mathrm{~cm}^{-1}$, respectively) are also visible and usually indicate the presence of defects in the graphitic lattice such as disordered carbons, edges and wrinkles [38,39]. Different atoms inserted in the graphitic lattice, such as substitutional nitrogen, can as well act as defects, in principle contributing to the D and D’ signal.

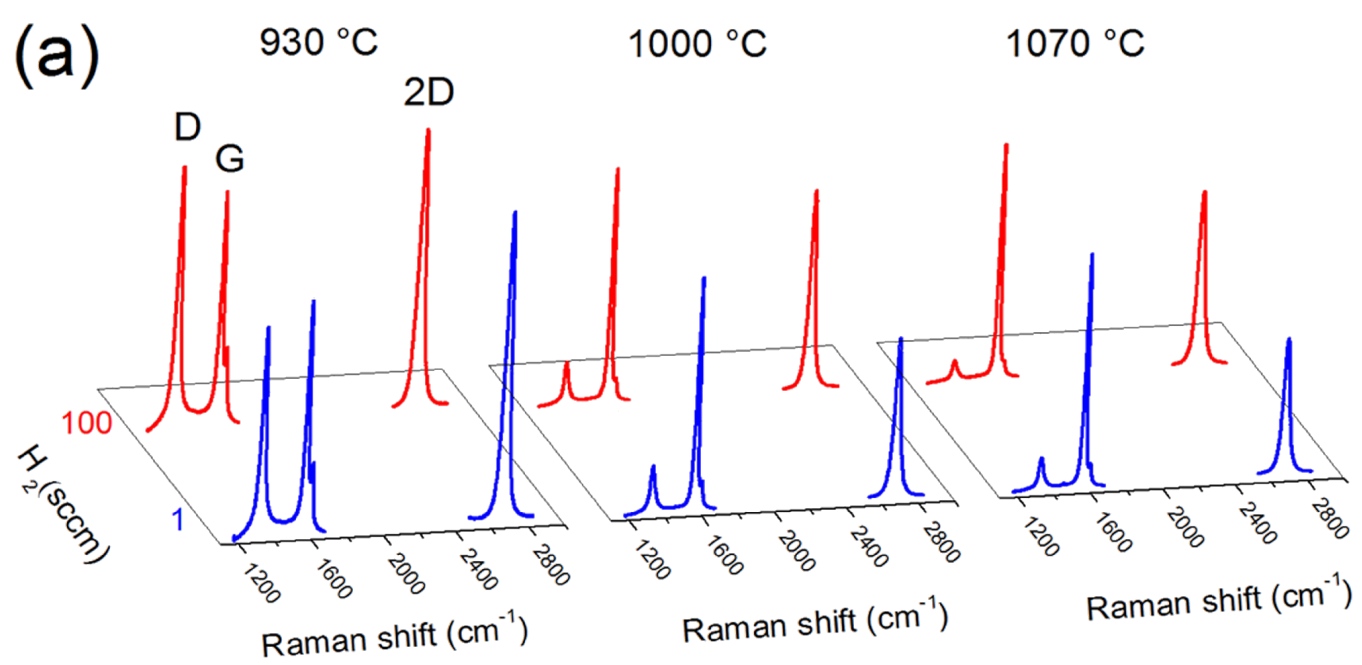

(b)

$930^{\circ} \mathrm{C}$

$1000^{\circ} \mathrm{C}$ $1070^{\circ} \mathrm{C}$

2D

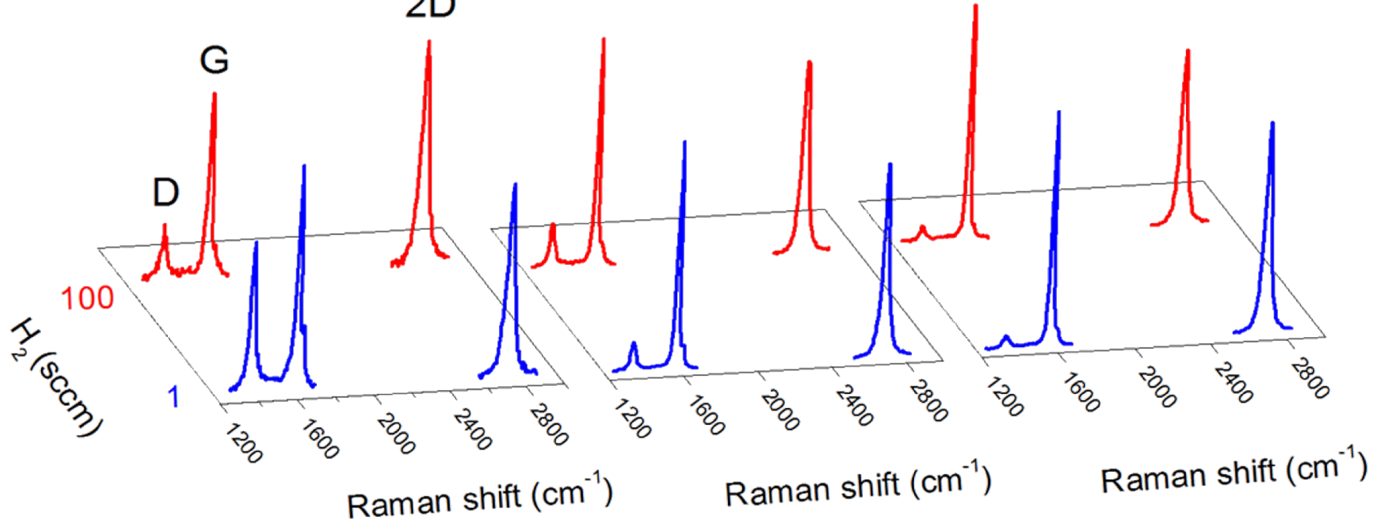

Figure 1: (a) Raman spectra of graphene grown by pyridine, at different temperatures and hydrogen flows. (b) Raman spectra of graphene grown by ethanol. 
In Figure 1 it appears that above $1000{ }^{\circ} \mathrm{C}$ the films have overall analogous Raman features. At $930{ }^{\circ} \mathrm{C}$ instead, the D and D' peaks become particularly intense, especially in the case of pyridine graphene.

The positions of the peaks and their intensity ratios $\left(I_{\mathrm{D} / \mathrm{G}}, I_{2 \mathrm{D} / \mathrm{G}}\right.$, $I_{\mathrm{D} / \mathrm{D}^{\prime}}$ ) are reported in Table S1 (Supporting Information File 1). The $I_{2 \mathrm{D}} / I_{\mathrm{G}}$ intensity ratios can be used to estimate the film thickness: single-layer and bi-layer graphene are characterized by $I_{2 \mathrm{D}} / I_{\mathrm{G}}>1$, whereas multilayer graphene typically has $I_{2 \mathrm{D}} / I_{\mathrm{G}}<1[40]$.

For pyridine-CVD, temperatures above $1000{ }^{\circ} \mathrm{C}$ seem to favor the growth of multilayer graphene $\left(I_{2 \mathrm{D}} / I_{\mathrm{G}}\right.$ ranging from 0.6 to 0.86), whereas at $930{ }^{\circ} \mathrm{C}$ the films seem to be composed of 1 to 3 layers $\left(I_{2 \mathrm{D}} / I_{\mathrm{G}}\right.$ between 1.29 and 1.55). This situation is in line with graphene grown through ethanol-CVD (see Table S2, Supporting Information File 1). As for the effect of hydrogen flow, at all the three temperatures hydrogen appears to have a weak influence on the peak positions and on the $I_{\mathrm{D}} / I_{\mathrm{G}}$ ratio. This is in contrast with what usually reported for ethanol-CVD, where the role of hydrogen was found to be crucial in determining the crystalline quality and defect density of the graphene films $[30,31]$.

Concerning the $\mathrm{D}$ and $\mathrm{D}^{\prime}$ peaks, the highest intensities are observed at the temperature of $930{ }^{\circ} \mathrm{C}\left(I_{\mathrm{D}} / I_{\mathrm{G}}\right.$ intensity of 0.92-1.16, see Table S1, Supporting Information File 1), possibly indicating the occurrence of nitrogen doping. Table S1 also reports the values of the graphene domain size $L_{\mathrm{a}}$ evaluated according to the relation $L_{\mathrm{a}}=\left(2.4 \times 10^{-10}\right) \lambda^{4}\left(I_{\mathrm{D}} / I_{\mathrm{G}}\right)^{-1}$ (with $\lambda$ being the Raman exicitation wavelength and $I_{\mathrm{D}} / I_{\mathrm{G}}$ integrated intensity ratio) [41]. The low $L_{\mathrm{a}}$ values obtained at $930^{\circ} \mathrm{C}$ indicate a low average inter-defect distance; however the narrow full width half maximum (FWHM) of $\approx 28 \mathrm{~cm}^{-1}$ seems to point out that these highly dense defects should belong to a single type [39]. Comparing the $930{ }^{\circ} \mathrm{C}$ values reported in Table S1 (Supporting Information File 1) for pyridine-CVD to those in Table S2 (Supporting Information File 1) for ethanol$\mathrm{CVD}$, the $I_{\mathrm{D} / \mathrm{G}}$ ratios of the samples grown by pyridine ( 0.92 at $1 \mathrm{sccm} \mathrm{H}_{2}$ and 1.16 at $\left.100 \mathrm{sccm} \mathrm{H}_{2}\right)$ are consistently higher than those of the ethanol samples $\left(0.68\right.$ at $1 \mathrm{sccm} \mathrm{H}_{2}$ and 0.25 at $100 \mathrm{sccm} \mathrm{H} \mathrm{H}_{2}$ ). This $I_{\mathrm{D}} / I_{\mathrm{G}}$ increment for pyridine-CVD might be thus ascribed to the insertion of nitrogen in the graphene film.

It was shown that the $I_{\mathrm{D}} / I_{\mathrm{D}}$, intensity ratio can be used experimentally to get information about the nature of defects in graphene [42]. The $I_{\mathrm{D}} / I_{\mathrm{D}}$, ratio is found to be maximal (about 13) for defects associated with $\mathrm{sp}^{3}$ hybridization. It decreases for vacancy-like defects (about 7), and reaches a minimum for boundary-like defects (about 3.5). In the spectra of the pyridineCVD films grown at $930{ }^{\circ} \mathrm{C}$, the values of $I_{\mathrm{D}} / I_{\mathrm{D}}$, (Table S1, Supporting Information File 1) are always smaller than 4.5. This seems to suggest the occurrence of boundary-like defects, which would be linked to the presence of nitrogen atoms, coordinated either in the lattice or along grain boundaries.
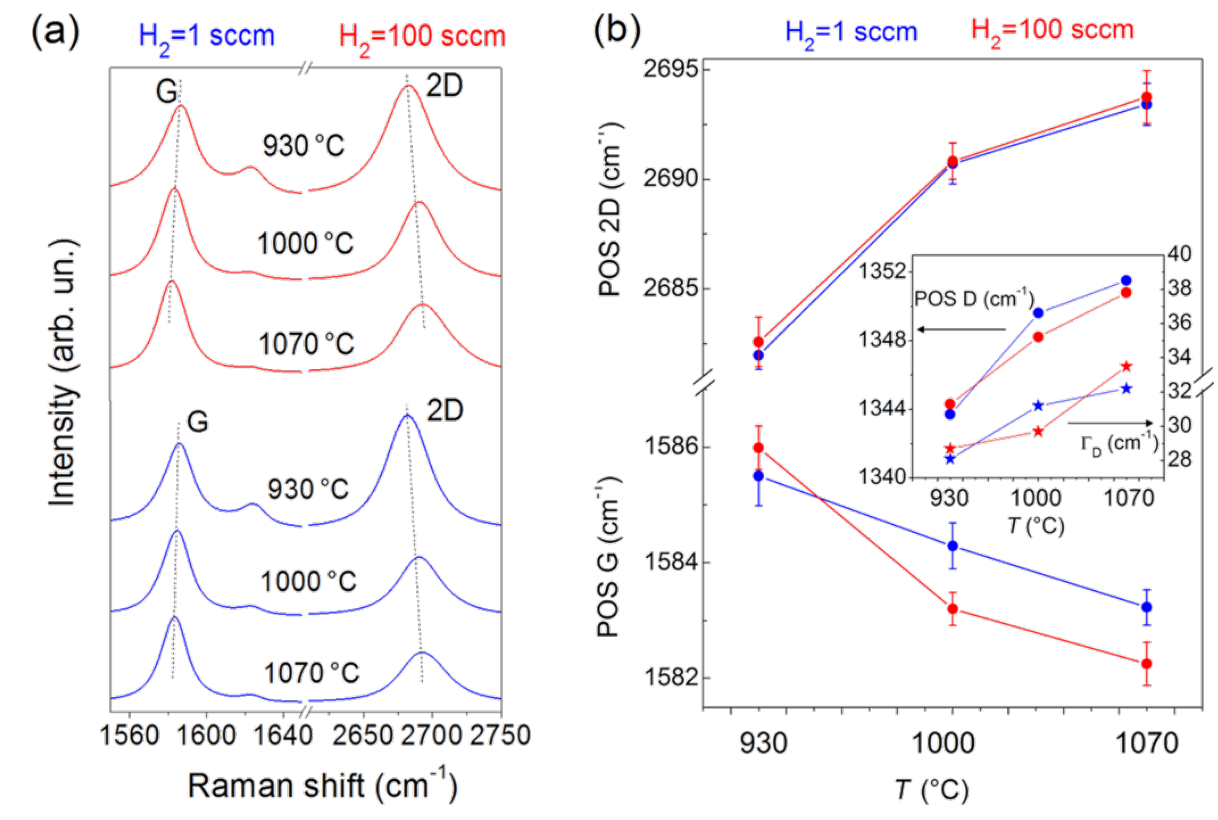

Figure 2: (a) Raman spectra of graphene samples grown with 1 and $100 \mathrm{sccm}$ of hydrogen flow,(b) position of the $\mathrm{G}$ and 2D peaks vs temperature (inset shows the shift of the $\mathrm{D}$ position and its corresponding $\Gamma$ variation). 
In Figure 2a, the influence of temperature and hydrogen flow on the $G$ and 2D Raman bands is further investigated. When lowering the CVD temperature, the position of the G peak is observed to slightly upshift, while the 2D peak position downshifts. Raman spectroscopy can monitor doping in graphene [43]. The $\mathrm{G}$ and 2D bands of graphene respond to doping and in particular, an upshift of the $G$ band usually demonstrates the occurrence of doping (holes or electrons) in graphene films, while the shift of the 2D band indicates the type of doping (n-type for a downshift, p-type for an upshift) [44]. The D band was also reported to vary with doping [45]. The authors reported that its frequency increases in the case of hole doping and decreases for the electron one, whereas, its FWHM increases at low carrier density doping (by both electrons and holes), but decreases for heavy electron doping [45]. In our samples, upon lowering the temperature, the D peak narrows and its frequency position decreases by about $7 \mathrm{~cm}^{-1}$ (inset in Figure $2 b$ ). All these results combined strongly suggest the occurrence of n-type doping, likely due to the introduction of nitrogen atoms into the carbon lattice.

Samples grown at $930{ }^{\circ} \mathrm{C}$ were further analyzed in detail by XPS (Figure 3). The wide spectrum in Figure 3 is typical of a pristine graphene transferred on $\mathrm{Si} / \mathrm{SiO}_{2}$, with the exception of an additional nitrogen component. The N1s peak, laying between $397-403 \mathrm{eV}$, was closely investigated. The peak is asymmetric and can be fitted with three components centered at 398.5, 400.4, $401.9 \mathrm{eV}$, which can be ascribed to pyridinic, quaternary (graphitic) [46] and oxidized $\mathrm{N}$ groups, respectively $[47,48]$. Pyridinic and quaternary are two of the three most common bonding configuration (both $\mathrm{sp}^{2}$ hybridized) for nitrogen within a carbon lattice (the third being pyrrolic, the only one that is $\mathrm{sp}^{3}$ hybridized) [28]. Specifically, $\mathrm{N}$ is in pyridinic configuration when it bonds with two $\mathrm{C}$ atoms sitting at an edge or a defect of the lattice (the $\mathrm{N}$ here contributes one electron to the $\pi$ system); in the quaternary configuration, instead, the $\mathrm{N}$ atom is inserted in the hexagonal ring substituting a $\mathrm{C}$ atom (and thus contributing two electrons to the $\pi$ system). The component assigned to oxidized $\mathrm{N}$ groups has been already observed in nitrogen-doped graphene and carbon nanotubes [49-51]: in this case, the $\mathrm{N}$ atom usually bonds with one $\mathrm{O}$ and two $\mathrm{C}$ atoms.

It should be noted that the curve deconvolution of the N1s spectra does not seem to show trace of pyrrolic $\mathrm{N}$, i.e., $\mathrm{N}$ atoms contributing two $\mathrm{p}$ electrons to the $\pi$ system (e.g., the kind of coordination an $\mathrm{N}$ atom has in the five-membered $\mathrm{C}$ ring of the pyrrole molecule). When present, the peak from pyrrolic $\mathrm{N}$ is expected to be located in between the pyridinic and quaternary peaks, at a distance of about 1.1-1.2 eV in binding energy from each of them [52]. In our XPS analysis, the quaternary peak is

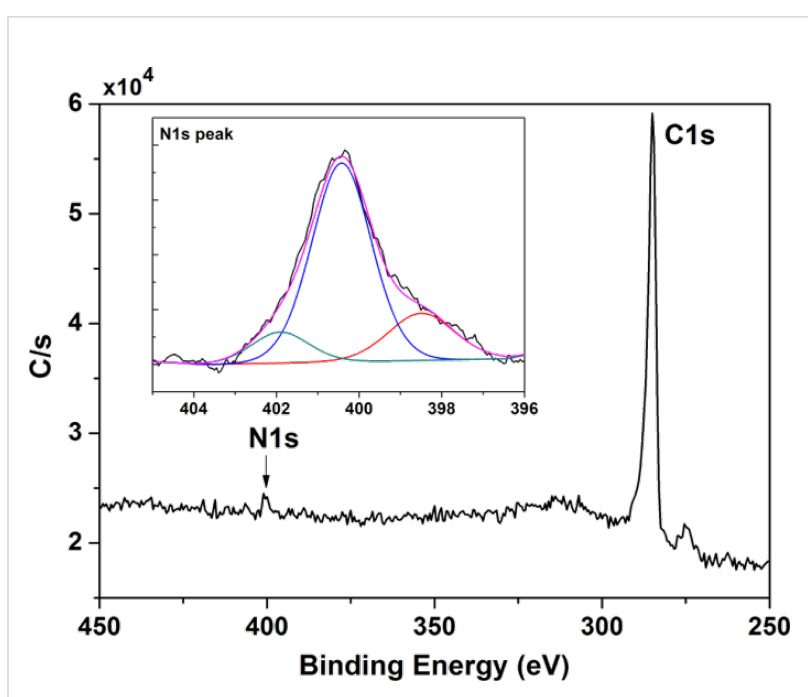

Figure 3: XPS spectrum of graphene grown by pyridine at $T=930^{\circ} \mathrm{C}$, $1 \mathrm{sccm} \mathrm{H}, 10 \mathrm{~min}$. The N1s peak is shown in the inset with a N/C ratio of about $2.9 \%$.

shifted by $1.9 \mathrm{eV}$ form the pyridinic peak (at $398.5 \mathrm{eV}$ ), in perfect agreement with similar experiments [53], and no further peak is revealed in between them. As for the oxidized N peak, this is shifted by $1.5 \mathrm{eV}$ from the quaternary peak, as already reported [51]. The absence of the pyrrolic $\mathrm{sp}^{3}$-hybridized component in XPS is found to be in agreement with the measured Raman $I_{\mathrm{D}} / I_{\mathrm{D}}$, ratio, which points only to $\mathrm{sp}^{2}$, boundary- or point-like defects.

The samples grown at 1000 and $1070{ }^{\circ} \mathrm{C}$ were also investigated by XPS. The $1000^{\circ} \mathrm{C}$ sample showed evidence of nitrogen, but the signal-to-noise was not high enough to reproducibly assess the $\mathrm{N} / \mathrm{C}$ content and/or ascertain the binding components. In the $1070{ }^{\circ} \mathrm{C}$ samples it was not possible to univocally determine the presence of nitrogen. Overall, the XPS spectra at each temperature were observed to be not affected by the hydrogen flow, as the Raman analysis.

\section{Characteristics of the films as transparent conductive electrodes}

\section{Sheet resistance and optical transmittance}

The graphene films were analyzed by atomic force microscopy (AFM) to investigate their morphology and evaluate their thickness (Figure 4). The films were found to uniformly adhere on the $\mathrm{Si} / \mathrm{SiO}_{2}$ surface. Occasionally, some folded regions can be found, as well as some wrinkles, as expected. The thickness was measured by taking profiles of the films grown at different temperatures. The measured values are in the range of about 1-2 nm, and a monotonic increase in thickness $(t)$ with the temperature is observed. All these results are consistent with the analysis of the Raman $I_{2 \mathrm{D}} / I_{\mathrm{G}}$ ratios. These values can be used to 

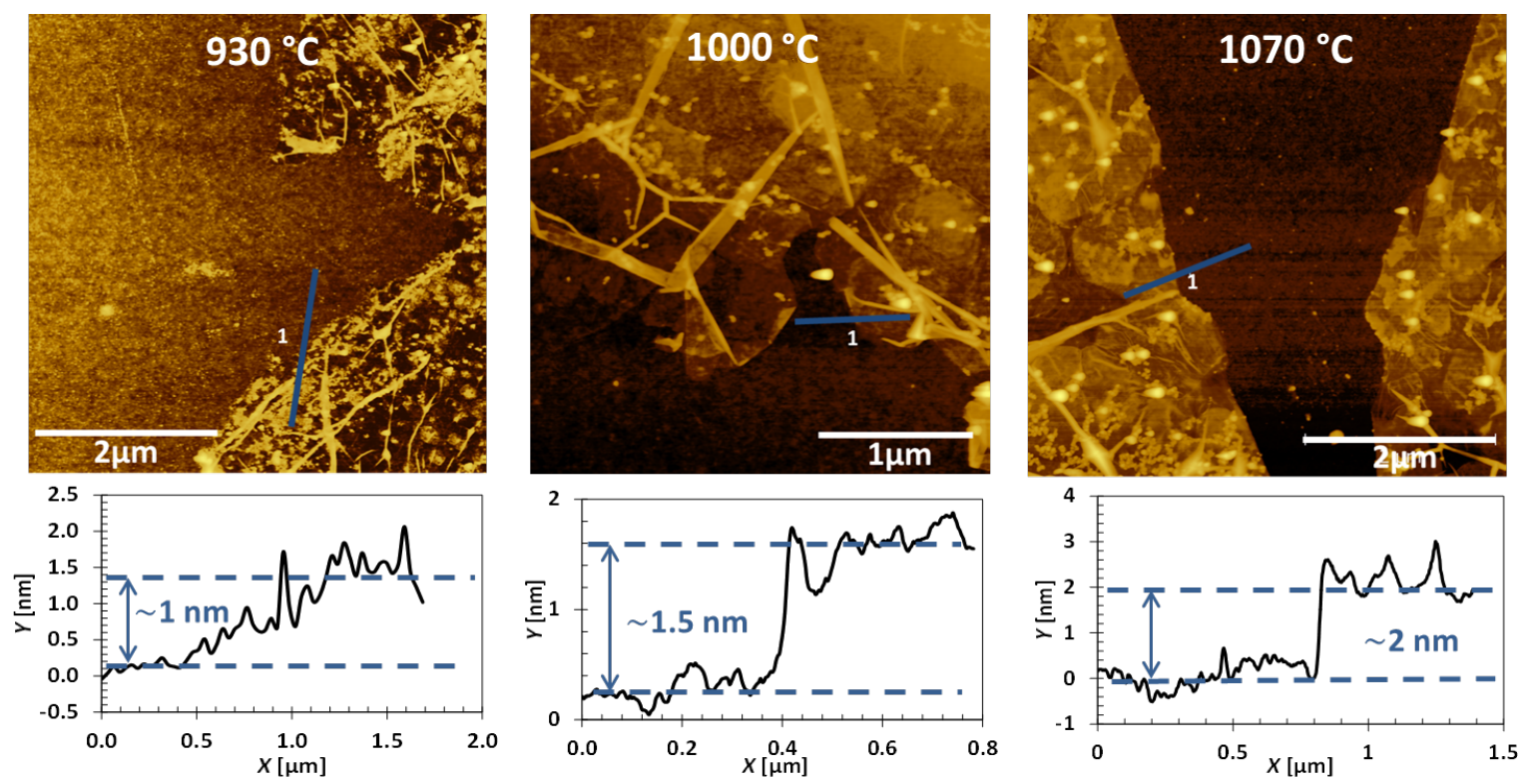

Figure 4: AFM micrographs of graphene films grown by pyridine-CVD for 10 min at 930,1000 and $1070{ }^{\circ} \mathrm{C}$. Line profiles, providing the film thickness of each sample, are displayed below the micrographs.

estimate the number of layers of the graphene films: $1-2$ at $930{ }^{\circ} \mathrm{C}, 3-4$ at $1000{ }^{\circ} \mathrm{C}$, and 6 at $1070{ }^{\circ} \mathrm{C}$.

In Table 1, the optical transmittance of the films is reported. The optical transmittance inversely scales with the CVD temperature, while it is not influenced by the hydrogen flow. The films grown at $930^{\circ} \mathrm{C}$ have all an average transmittance of $94 \%$ at $550 \mathrm{~nm}$, those grown at $1000{ }^{\circ} \mathrm{C}$ have $90 \%$, while the $1070{ }^{\circ} \mathrm{C}$ samples have $83 \%$.

\begin{tabular}{|c|c|c|c|}
\hline temperature $\left[{ }^{\circ} \mathrm{C}\right]$ & $T @ 550$ nm & $t[\mathrm{~nm}]$ & $\sigma_{O p}\left(\cdot 10^{5}\right) \mathrm{S} / \mathrm{m}$ \\
\hline 930 & 0.94 & 0.9 & 2.4 \\
\hline 1000 & 0.90 & 1.3 & 2.1 \\
\hline 1070 & 0.83 & 2.1 & 2.5 \\
\hline
\end{tabular}

The optical conductivity was calculated as $T=\left(1+Z_{0} / 2\right.$ $\left.\sigma_{\mathrm{Op}} \cdot t\right)^{-2}$, where $Z_{0}$ is the impedance of free space (equal to $377 \Omega$ ) [54], and $t$ is the thickness. The value of $t$ at each temperature was set taking in consideration the maximum number of layers as estimated by AFM and the optical transmittance of the film. This is a conservative approach, as the graphene films can occasionally appear thicker when analyzed by AFM in tapping mode [55]. Considering the thickness of a monolayer graphene (equal to $0.335 \mathrm{~nm}$ ), we have $t_{930}{ }^{\circ} \mathrm{C}=$ $0.9 \mathrm{~nm}, t_{1000}{ }^{\circ} \mathrm{C}=1.3 \mathrm{~nm}, t_{1070}{ }^{\circ} \mathrm{C}=2.1 \mathrm{~nm}[16]$.
We plotted the optical transmittance vs the CVD temperature for ethanol- and pyridine-grown films (Figure 5) to gain further insight into the two processes. The optical transmittance at $550 \mathrm{~nm}$ and the film thickness were found to be more sensitive to the temperature for the pyridine than for the ethanol case, indicating different kinetics. This effect might be related to the presence of oxygen in the ethanol precursor, which alters the

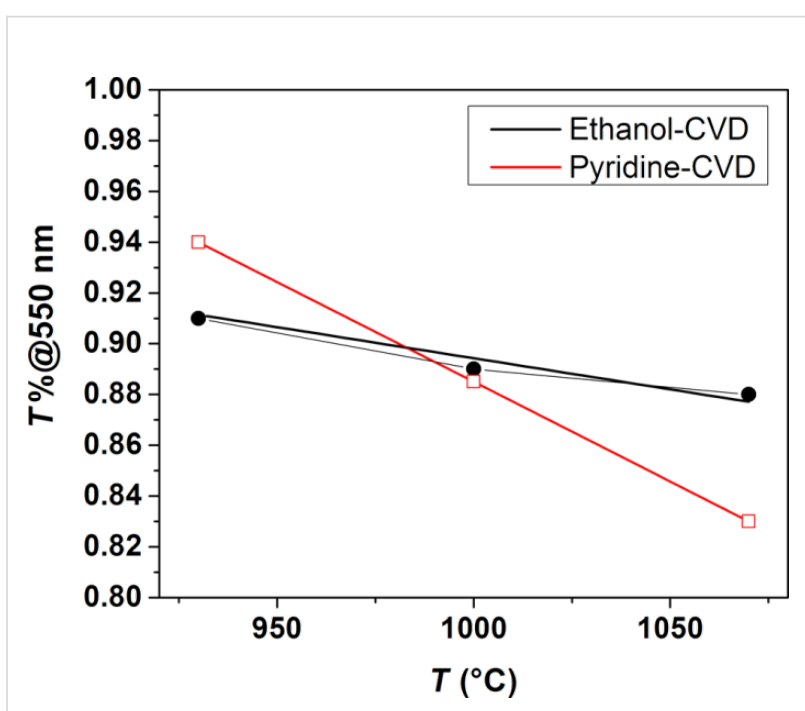

Figure 5: Transmittance vs CVD temperature trends of the graphene films. Data points are provided as red void squares (pyridine-CVD) and black filled circles (ethanol-CVD). The $T \%-v s-T\left({ }^{\circ} \mathrm{C}\right)$ dependence can be linearly fitted by $T_{\%}=(1.66-7.8) \cdot 10^{-4} T\left({ }^{\circ} \mathrm{C}\right)$ for pyridine-CVD and $T_{\%}=(1.14-2.5) \cdot 10^{-4} T\left({ }^{\circ} \mathrm{C}\right)$ for ethanol-CVD. 
catalytic activity of copper $[37,56]$. The two liquid precursors could be thus selected to be used at a specific temperature to obtain graphene films of different thickness.

The electrical properties of the graphene films grown by pyridine-CVD are reported in Table 2 . The electrical conductivity is linked to the film thickness as $R_{\mathrm{S}}=\left(\sigma_{\mathrm{DC}} \cdot \mathrm{t}\right)^{-1}$. We have also calculated a figure of merit (FoM) that can be used to compare the electrical/optical properties of thin transparent conductors made from various materials. Such FoM is defined as the conductivity ratio, $\sigma_{\mathrm{DC}} / \sigma_{\mathrm{Op}}[16]$.

The temperature is the main parameter dictating the characteristics of the pyridine-CVD graphene films, as also observed for the optical properties and the thickness of the films. At each temperature, the sheet resistance is observed to sweep over a narrow range of values when adding the two different hydrogen flows. Hydrogen seems to lead to a slight decrease in sheet resistance at 1000 and $1070{ }^{\circ} \mathrm{C}$, while this trend is reversed at $930{ }^{\circ} \mathrm{C}$. The electrical characteristics of the pyridine films can be compared to those of ethanol-CVD graphene in Table 3. In this case, the samples with the lowest sheet resistance at each temperature are reported (obtained with specific hydrogen flows, as indicated in the table). As in the case of pyridineCVD, the optical transmittance decreases with the temperature, as does the sheet resistance.

To account for the intrinsic electrical properties of the graphene films, without reference to the thickness, a study of their elec- trical conductivity is in order. Overall, the electrical conductivity of graphene from both pyridine and ethanol is observed to increase with the CVD temperature, as expected (and as demonstrated by the progressively lower D peak in the Raman spectra) [30,57]. At $1070{ }^{\circ} \mathrm{C}$, the films show similar thicknesses (around $2 \mathrm{~nm}$ ) and electrical conductivities ( $\sigma_{\mathrm{DC}}$ up to $11.9 \cdot 10^{5} \mathrm{~S} / \mathrm{m}$ for the pyridine sample). This points to a negligible effect of doping in the pyridine samples at $1070{ }^{\circ} \mathrm{C}$, as confirmed by Raman and XPS, and as expected at such a high temperature [27].

Upon lowering the temperature to $1000{ }^{\circ} \mathrm{C}$, some differences in the two kinds of graphene films emerge and a weak effect of doping can be detected in the pyridine-derived films (also confirmed by Raman and XPS analysis). With the CVD of ethanol, at 1070 and at $1000{ }^{\circ} \mathrm{C}$ pristine graphene films were grown with the same conductivity ( $\sigma_{\mathrm{DC}}$ up to $10.4 \cdot 10^{5} \mathrm{~S} / \mathrm{m}$ ). Instead, in the case of pyridine, the film grown at $1070{ }^{\circ} \mathrm{C}$ has a lower conductivity $\left(11.9 \cdot 10^{5} \cdot \mathrm{S} / \mathrm{m}\right)$ than the film grown at $1000{ }^{\circ} \mathrm{C}\left(14.3 \cdot 10^{5} \mathrm{~S} / \mathrm{m}\right)$. Upon decreasing the temperature to $930{ }^{\circ} \mathrm{C}$, the electrical conductivity of the samples from both precursors decreases due to the evident defectiveness of the growth at such low temperature (Table S1, Supporting Information File 1). But, the pyridine samples at $930{ }^{\circ} \mathrm{C}$ have an electrical conductivity that is $40 \%$ higher than that of the ethanolderived samples $\left(6 \cdot 10^{5} \mathrm{~S} / \mathrm{m}\right.$ compared to $\left.4.3 \cdot 10^{5}\right)$. This situation strongly supports the occurrence of nitrogen doping during pyridine-CVD below $1000{ }^{\circ} \mathrm{C}$, and in particular at $930{ }^{\circ} \mathrm{C}$, as evidenced previously by the Raman and XPS analysis. Such

\begin{tabular}{|c|c|c|c|c|c|c|}
\hline \multirow[b]{2}{*}{ temperature $\left[{ }^{\circ} \mathrm{C}\right]$} & \multicolumn{3}{|c|}{$\mathrm{H}_{2}$ flow: $1 \mathrm{sccm}$} & \multicolumn{3}{|c|}{ H2 flow: $100 \mathrm{sccm}$} \\
\hline & $R_{\mathrm{S}}[\mathrm{k} \Omega / \square]$ & $\sigma_{D C}\left[10^{5} \mathrm{~S} / \mathrm{m}\right]$ & FoM & $R_{\mathrm{S}}[\mathrm{k} \Omega / \square]$ & $\sigma_{\mathrm{DC}}\left[10^{5} \mathrm{~S} / \mathrm{m}\right]$ & FoM \\
\hline 930 & 2.4 & 6 & 2.5 & 3.2 & 4.5 & 1.9 \\
\hline 1000 & 0.9 & 8 & 3.9 & 0.5 & 14.3 & 7 \\
\hline 1070 & 0.65 & 7.3 & 3 & 0.4 & 11.9 & 4.8 \\
\hline
\end{tabular}

Table 3: Electrical properties of the ethanol-CVD graphene.

\begin{tabular}{|c|c|c|c|c|c|c|c|c|}
\hline $\begin{array}{l}\text { temperature } \\
{\left[{ }^{\circ} \mathrm{C}\right]}\end{array}$ & $\begin{array}{l}\mathrm{H}_{2} \\
\text { [sccm] }\end{array}$ & $\begin{array}{l}T @ 550 \\
{[\mathrm{~nm}]}\end{array}$ & $\begin{array}{l}\text { number of } \\
\text { layers }\end{array}$ & $\begin{array}{l}\text { thickness } \\
{[\mathrm{nm}]}\end{array}$ & $\begin{array}{l}\sigma_{O p} \\
{\left[10^{5} \mathrm{~S} / \mathrm{m}\right]}\end{array}$ & $\begin{array}{l}R_{\mathrm{S}} \\
{[\mathrm{k} \Omega / \square]}\end{array}$ & $\begin{array}{l}\sigma_{\mathrm{DC}} \\
{\left[10^{5} \mathrm{~S} / \mathrm{m}\right]}\end{array}$ & FoM \\
\hline 930 & 0 & 0.91 & 4 & 1.3 & 2 & 1.8 & 4.3 & 2.2 \\
\hline 1000 & 100 & 0.89 & 5 & 1.6 & 2 & 0.6 & 10.4 & 5.2 \\
\hline 1070 & 10 & 0.86 & 6 & 2.0 & 2.1 & 0.5 & 10 & 4.8 \\
\hline
\end{tabular}


values of electrical conductivity also demonstrate that the $I_{\mathrm{D} / \mathrm{G}}$ Raman ratios observed in pyridine-derived graphene, which are higher than those of ethanol-derived graphene, are due to quaternary nitrogen doping and not to a more defective graphene lattice. In fact, a defective lattice would rather impair the electrical conductivity making it lower than that of ethanolCVD graphene [57]. With regard to the FoMs (Table 2 and Table 3), the pyridine samples consistently achieve higher FoMs than the ethanol samples (up to 7 at $1000{ }^{\circ} \mathrm{C}$ ), suggesting the viable use of pyridine as CVD precursor for the production of efficient transparent conductive electrodes.

The interpretation of the experimental evidence gathered in our analysis can be used to draw some general conclusions about the characteristics of the films grown by pyridine-CVD, in view of their application in electronics. i) The film thickness is directly proportional to the CVD temperature. ii) The electrical conductivity generally improves when increasing the CVD temperature and hydrogen flow, due to a higher graphitization level and to a lower defect density. iii) The electrical conductivity is also linked to the doping level, which is however less pronounced above $1000{ }^{\circ} \mathrm{C}$.

\section{Conclusion}

Graphene films were grown by chemical vapour deposition (CVD) using pyridine as liquid carbon precursor, exploring a range of temperatures between 930 and $1070{ }^{\circ} \mathrm{C}$, and assessing the effect of hydrogen in the CVD gas mixture. A comprehensive range of characterizations (atomic force microscopy, Raman and X-ray photoemission spectroscopy, optical and electrical measurements) was run to ascertain the properties of the graphene samples and the occurrence of doping. These results were compared to the case of pristine graphene films grown by CVD of ethanol, a liquid precursor akin to pyridine. The graphene films grown at high temperatures $\left(1070{ }^{\circ} \mathrm{C}\right)$ are in both cases multilayered with high crystalline quality. Upon lowering the temperature below $1000{ }^{\circ} \mathrm{C}$, the graphene films are on average thinner (down to one or two layers) and with a higher defect density. In particular, at $930^{\circ} \mathrm{C}$ significant differences emerge in the Raman spectra of the graphene films grown by the two precursors: the pyridine samples show G, 2D and D band shift which are usually ascribed to n-type doping, while the ethanol samples do not show such trends. XPS spectra confirmed the presence of nitrogen in pyridine-films grown at temperatures below $1000{ }^{\circ} \mathrm{C}$. Graphene grown from pyridine at $930{ }^{\circ} \mathrm{C}$ (with $1 \mathrm{sccm}$ of hydrogen flow) had a nitrogen/carbon ratio of $3 \%$, and from the N1s peak analysis the nitrogen atoms appear in quaternary form (i.e., inserted into the graphitic lattice). We conclude that when the CVD temperature is lowered below $1000{ }^{\circ} \mathrm{C}$, non-carbon atoms or groups can insert in the $\mathrm{C}$ lattice forming doped graphene. As a result, below
$1000{ }^{\circ} \mathrm{C}$ the effect of nitrogen doping emerges among these effects and contributes to bring the electrical conductivity of the pyridine samples up to $14.3 \cdot 10^{5} \mathrm{~S} / \mathrm{m}$, i.e., consistently higher values than the pristine samples grown by ethanol-CVD.

\section{Experimental Graphene growth and transfer}

Graphene films were grown onto $25 \mu \mathrm{m}$ thick copper foil $(\mathrm{Cu}-$ XLP/PHC Extra low phosphorous copper, $99.95 \%$ purity) cut to the desired size and placed over a quartz boat, after cleaning with acetone and ethanol.

Graphene was grown in a low-pressure CVD reactor and the graphene films were transferred onto the substrates of use by a wet transfer method. The reactor consists of a $2 \mathrm{~m}$ long, $38 \mathrm{~mm}$ inner diameter quartz tube, coaxial to a high temperature furnace. The tube is connected to a rotary vane vacuum pump, a mass flow controlled gas feed system and absolute pressure gauges. The long reactor tube allows the samples to be inserted in and extracted from the heated section without breaking the vacuum or perturbing the gaseous atmosphere. The system design implements a fast cooling scheme allowing several samples to be grown within a single furnace heating cycle, without exposing them to the atmosphere when hot. After the initial ramping of the furnace temperature the pressure was stabilised at 4 mbar by flowing $20 \mathrm{sccm}$ Ar and $20 \mathrm{sccm} \mathrm{H}_{2}$. The quartz boat supporting the samples was then inserted into the hot zone and annealed for $1200 \mathrm{~s}$ at the growth temperature. Liquid pyridine was contained in a steel "bubbler" vessel pressurized in Ar at 3 bar, which was kept at $20^{\circ} \mathrm{C}$ (about 15 mbar equilibrium pressure). After the annealing, the $\mathrm{H}_{2}$ gas flow was set to the desired value and the Ar flow was switched from the bubbler vessel at a flow rate of $20 \mathrm{sccm}$. The amount of vapor entering the chamber was estimated to be $0.5 \%$ (15 mbar/3 bar) of the carrier flow, thus $0.1 \mathrm{sccm}$. After the desired growth time, the samples were extracted from the hot zone, let to cool to near room temperature, and then extracted from the vacuum vessel and further processed for extracting the graphene. When performing the growth with ethanol, the procedure was the same, with the only difference being that the steel "bubbler" vessel in this case contained liquid ethanol (pressurized in Ar at 3 bar) and was kept at $0{ }^{\circ} \mathrm{C}$. It can be noted that the CVD of pyridine requires the same experimental setup as the CVD of ethanol, being both precursors liquid under standard conditions and having similar vapor pressures (about $15 \mathrm{mbar}$ at $20^{\circ} \mathrm{C}$ for pyridine and at $0{ }^{\circ} \mathrm{C}$ for ethanol).

Graphene was transferred onto $300 \mathrm{~nm}$ thermal oxide-coated $\mathrm{Si}$ wafers for Raman, XPS, AFM and sheet resistance measurements, and onto glass substrates for optical transmittance. The graphene transfer was performed using a cyclododecane protec- 
tive layer, a novel method recently developed by our group. Cyclododecane is a waxy solid which sublimates at ambient temperature in a few hours without leaving residues and it was recently demonstrated not to alter Raman nor XPS spectrum of graphene when used, with respects to the free floating method [36]. To further check this point, Raman and XPS spectra were also recorded on samples transferred by free-floating with the same results. The copper foil was etched away by means of an ammonium persulfate bath (PSA, 50g/L) for $3 \mathrm{~h}$ at about $20^{\circ} \mathrm{C}$ and then transferred in a clean distilled water bath for rinsing. The graphene film was finally scooped out of the distilled water using the destination substrate for its subsequent characterization and use.

\section{Film characterization Raman spectroscopy}

Doping level, degree of $\mathrm{sp}^{2}$ crystallinity and mechanical strain were investigated using Raman spectroscopy, with a HORIBA Scientific LabRAM HR Evolution Raman spectrometer with an integrated Olympus BX41 microscope. Laser excitation wavelength of $532 \mathrm{~nm}(2.33 \mathrm{eV})$ was focused on the sample surface using a $100 \times$ objective with a spot size of approximately $1 \mu \mathrm{m}$. Low laser power (below $1 \mathrm{~mW}$ ) was used to minimize sample heating and possible damages. Because of possible inhomogeneity in the films, the spectra were recorded at ten different spots and averaged.

\section{XPS}

The electronic and structural properties of the graphene films on $\mathrm{Si} / \mathrm{SiO}_{2}$ were probed by X-ray photoemission spectroscopy (XPS) with $\mathrm{Mg} \mathrm{K} \alpha$ X-ray radiation at $1253.6 \mathrm{eV}$ (VG Escalab MkII Spectrometer). The samples were treated in air at $200{ }^{\circ} \mathrm{C}$ for a few minutes before XPS to remove possible organic contaminants.

\section{AFM}

Graphene-films transferred on silicon have been characterized by tapping-mode atomic force microscopy (using a BrukerVeeco Dimension Icon AFM). The images were acquired in tapping mode at $0.5 \mathrm{~Hz}$, using Sb-doped Si cantilevers (Bruker) with resonant frequency around $300 \mathrm{kHz}$. At least five areas for each sample were measured in order to take into account thickness inhomogeneity which might derive from the film transfer (the AFM images shown in Figure 4 are statistically representative of these measurement).

\section{Sheet resistance measurement}

The electrical sheet resistance of the films transferred to $\mathrm{Si} / \mathrm{SiO}_{2}$ was measured in a controlled environment under constant temperature $\left(23 \pm 0.5^{\circ} \mathrm{C}\right)$ and humidity $(35 \pm 5 \%)$. The test system consisted of a probe with four collinear WC tips (spaced overall by $3 \mathrm{~mm}$ ), fixed on a stand (Signatone S301) and connected to a current source and a low-voltage meter. The measurements were repeated multiple times over an area of at least $1 \times 1 \mathrm{~cm}^{2}$ on each sample and then averaged.

\section{Optical transmittance}

Transmittance spectra at normal incidence have been recorded in the 400-1100 $\mathrm{nm}$ wavelength range by a fiber optics spectrophotometer (HR4000CG-UV-NIR model by Ocean Optics), equipped with a tungsten halogen source and connected to the sample stage by quartz optical fibers $(1 \mathrm{~m}$ length, $600 \mu \mathrm{m}$ core diameter) with quartz collimating lens mounted on their ends (spot size on the sample about $1 \mathrm{~mm}$ ). For each sample, the measurement was repeated in three sites to average over film inhomogeneity.

\section{Supporting Information}

In the Supporting Information the results of the Raman spectral fitting for pyridine- and ethanol-CVD are reported.

\section{Supporting Information File 1}

Results of the Raman spectral fittings.

[http://www.beilstein-journals.org/bjnano/content/ supplementary/2190-4286-6-206-S1.pdf]

\section{References}

1. Stadler, A. Materials 2012, 5, 661-683. doi:10.3390/ma5040661

2. Schubert, E. F.; Gessmann, T.; Kim, J. K. Inorganic Semiconductors for Light-emitting Diodes. Organic Light Emitting Devices; Wiley-VCH Verlag GmbH \& Co. KGaA, 2006; pp 1-33. doi:10.1002/3527607986.ch1

3. Green, M. A.; Emery, K.; Hishikawa, Y.; Warta, W.; Dunlop, E. D. Prog. Photovoltaics 2013, 21, 1-11. doi:10.1002/pip.2352

4. Hoppe, H.; Sariciftci, N. S. J. Mater. Res. 2004, 19, 1924-1945. doi:10.1557/JMR.2004.0252

5. O'Regan, B.; Grätzel, M. Nature 1991, 353, 737-740. doi:10.1038/353737a0

6. Capasso, A.; Salamandra, L.; Di Carlo, A.; Bell, J. M.; Motta, N. Beilstein J. Nanotechnol. 2012, 3, 524-532. doi:10.3762/bjnano.3.60

7. Zardetto, V.; Brown, T. M.; Reale, A.; Di Carlo, A. J. Polym. Sci., Part B: Polym. Phys. 2011, 49, 638-648. doi:10.1002/polb.22227

8. Capasso, A.; Salamandra, L.; Chou, A.; Di Carlo, A.; Motta, N. Sol. Energy Mater. Sol. Cells 2014, 122, 297-302. doi:10.1016/j.solmat.2013.10.022

9. Novoselov, K. S.; Geim, A. K.; Morozov, S. V.; Jiang, D.; Katsnelson, M. I.; Grigorieva, I. V.; Dubonos, S. V.; Firsov, A. A. Nature 2005, 438, 197-200. doi:10.1038/nature04233

10. Geim, A. K.; Novoselov, K. S. Nat. Mater. 2007, 6, 183-191. doi:10.1038/nmat1849

11. Novoselov, K. S.; Fal'ko, V. I.; Colombo, L.; Gellert, P. R.; Schwab, M. G.; Kim, K. Nature 2012, 490, 192-200. doi:10.1038/nature11458 
12. Ferrari, A. C.; Bonaccorso, F.; Fal'ko, V.; Novoselov, K. S.; Roche, S.; Bøggild, P.; Borini, S.; Koppens, F. H. L.; Palermo, V.; Pugno, N.; Garrido, J. A.; Sordan, R.; Bianco, A.; Ballerini, L.; Prato, M.; Lidorikis, E.; Kivioja, J.; Marinelli, C.; Ryhänen, T.; Morpurgo, A.; Coleman, J. N.; Nicolosi, V.; Colombo, L.; Fert, A.; Garcia-Hernandez, M.; Bachtold, A.; Schneider, G. F.; Guinea, F.; Dekker, C.; Barbone, M.; Sun, Z.; Galiotis, C.; Grigorenko, A. N.; Konstantatos, G.; Kis, A.; Katsnelson, M.; Vandersypen, L.; Loiseau, A.; Morandi, V.; Neumaier, D.; Treossi, E.; Pellegrini, V.; Polini, M.; Tredicucci, A.; Williams, G. M.; Hee Hong, B.; Ahn, J.-H.; Min Kim, J.; Zirath, H.; van Wees, B. J.; van der Zant, H.; Occhipinti, L.; Di Matteo, A.; Kinloch, I. A.; Seyller, T.; Quesnel, E.; Feng, X.; Teo, K.; Rupesinghe, N.; Hakonen, P.; Neil, S. R. T.; Tannock, Q.; Löfwander, T.; Kinaret, J. Nanoscale 2015, 7, 4598-4810. doi:10.1039/C4NR01600A

13. Zhang, Y.; Zhang, L.; Zhou, C. Acc. Chem. Res. 2013, 46, 2329-2339. doi:10.1021/ar300203n

14. Mattevi, C.; Kim, H.; Chhowalla, M. J. Mater. Chem. 2011, 21 , 3324-3334. doi:10.1039/C0JM02126A

15. Yan, Z.; Peng, Z.; Tour, J. M. Acc. Chem. Res. 2014, 47, 1327-1337. doi:10.1021/ar4003043

16. De, S.; Coleman, J. N. ACS Nano 2010, 4, 2713-2720. doi: $10.1021 / \mathrm{nn} 100343 \mathrm{f}$

17. Chen, J.-H.; Jang, C.; Adam, S.; Fuhrer, M. S.; Williams, E. D.; Ishigami, M. Nat. Phys. 2008, 4, 377-381. doi:10.1038/nphys935

18. Shlimak, I.; Haran, A.; Zion, E.; Havdala, T.; Kaganovskii, Yu.; Butenko, A. V.; Wolfson, L.; Richter, V.; Naveh, D.; Sharoni, A.; Kogan, E.; Kaveh, M. Phys. Rev. B 2015, 91, 045414. doi:10.1103/PhysRevB.91.045414

19. Giovannetti, G.; Khomyakov, P. A.; Brocks, G.; Karpan, V. M.; van den Brink, J.; Kelly, P. J. Phys. Rev. Lett. 2008, 101, 026803. doi:10.1103/PhysRevLett.101.026803

20. Chen, W.; Chen, S.; Qi, D. C.; Gao, X. Y.; Wee, A. T. S. J. Am. Chem. Soc. 2007, 129, 10418-10422. doi:10.1021/ja071658g

21. Gao, H.; Liu, Z.; Song, L.; Guo, W.; Gao, W.; Ci, L.; Rao, A.; Quan, W.; Vajtai, R.; Ajayan, P. M. Nanotechnology 2012, 23, 275605. doi:10.1088/0957-4484/23/27/275605

22. Kim, K. K.; Reina, A.; Shi, Y.; Park, H.; Li, L.-J.; Lee, Y. H.; Kong, J. Nanotechnology 2010, 21, 285205. doi:10.1088/0957-4484/21/28/285205

23. Panchokarla, L. S.; Subrahmanyam, K. S.; Saha, S. K.; Govindaraj, A.; Krishnamurthy, H. R.; Waghmare, U. V.; Rao, C. N. R. Adv. Mater. 2009, 21, 4726-4730. doi:10.1002/adma.200901285

24. Qu, L.; Liu, Y.; Baek, J.-B.; Dai, L. ACS Nano 2010, 4, 1321-1326. doi:10.1021/nn901850u

25. Reddy, A. L. M.; Srivastava, A.; Gowda, S. R.; Gullapalli, H.; Dubey, M.; Ajayan, P. M. ACS Nano 2010, 4, 6337-6342. doi:10.1021/nn101926g

26. Luo, Z.; Lim, S.; Tian, Z.; Shang, J.; Lai, L.; MacDonald, B.; Fu, C.; Shen, Z.; Yu, T.; Lin, J. J. Mater. Chem. 2011, 21, 8038-8044. doi:10.1039/c1jm10845j

27. Imamura, G.; Saiki, K. J. Phys. Chem. C 2011, 115, 10000-10005. doi:10.1021/jp202128f

28. Wang, H.; Maiyalagan, T.; Wang, X. ACS Catal. 2012, 2, 781-794. doi:10.1021/cs200652y

29. Gao, H.; Song, L.; Guo, W.; Huang, L.; Yang, D.; Wang, F.; Zuo, Y.; Fan, X.; Liu, Z.; Gao, W.; Vajtai, R.; Hackenberg, K.; Ajayan, P. M. Carbon 2012, 50, 4476-4482. doi:10.1016/j.carbon.2012.05.026
30. Faggio, G.; Capasso, A.; Messina, G.; Santangelo, S.; Dikonimos, Th.; Gagliardi, S.; Giorgi, R.; Morandi, V.; Ortolani, L.; Lisi, N. J. Phys. Chem. C 2013, 117, 21569-21576. doi:10.1021/jp407013y

31. Santangelo, S.; Messina, G.; Malara, A.; Lisi, N.; Dikonimos, T.; Capasso, A.; Ortolani, L.; Morandi, V.; Faggio, G. Diamond Relat. Mater. 2014, 41, 73-78. doi:10.1016/j.diamond.2013.11.006

32. Paul, R. K.; Badhulika, S.; Niyogi, S.; Haddon, R. C.; Boddu, V. M.; Costales-Nieves, C.; Bozhilov, K. N.; Mulchandani, A. Carbon 2011, 49, 3789-3795. doi:10.1016/j.carbon.2011.04.070

33. Li, J.; Kazakov, A.; Dryer, F. L. J. Phys. Chem. A 2004, 108, 7671-7680. doi:10.1021/jp0480302

34. Hurd, C. D.; Simon, J. I. J. Am. Chem. Soc. 1962, 84, 4519-4524. doi:10.1021/ja00882a030

35. Jin, Z.; Yao, J.; Kittrell, C.; Tour, J. M. ACS Nano 2011, 5, 4112-4117. doi:10.1021/nn200766e

36. Capasso, A.; De Francesco, M.; Leoni, E.; Dikonimos, T.; Buonocore, F.; Lancellotti, L.; Bobeico, E.; Sarto, M. S.; Tamburrano, A.; De Bellis, G.; Lisi, N. Appl. Phys. Lett. 2014, 105, 113101. doi:10.1063/1.4895733

37. Lisi, N.; Buonocore, F.; Dikonimos, Th.; Leoni, E.; Faggio, G.; Messina, G.; Morandi, V.; Ortolani, L.; Capasso, A. Thin Solid Films 2014, 571, Part 1, 139-144. doi:10.1016/j.tsf.2014.09.040

38. Ferrari, A. C.; Meyer, J. C.; Scardaci, V.; Casiraghi, C.; Lazzeri, M.; Mauri, F.; Piscanec, S.; Jiang, D.; Novoselov, K. S.; Roth, S.; Geim, A. K. Phys. Rev. Lett. 2006, 97, 187401. doi:10.1103/PhysRevLett.97.187401

39. Pimenta, M. A.; Dresselhaus, G.; Dresselhaus, M. S.; Cançado, L. G.; Jorio, A.; Saito, R. Phys. Chem. Chem. Phys. 2007, 9, 1276-1290. doi:10.1039/b613962k

40. Reina, A.; Jia, X.; Ho, J.; Nezich, D.; Son, H.; Bulovic, V.; Dresselhaus, M. S.; Kong, J. Nano Lett. 2009, 9, 30-35. doi:10.1021/nl801827v

41. Cancado, L. G.; Takai, K.; Enoki, T.; Endo, M.; Kim, Y. A.; Mizusaki, H.; Jorio, A.; Coelho, L. N.; Magalhães-Paniago, R.; Pimenta, M. A. Appl. Phys. Lett. 2006, 88, 163106. doi:10.1063/1.2196057

42. Eckmann, A.; Felten, A.; Mishchenko, A.; Britnell, L.; Krupke, R.; Novoselov, K. S.; Casiraghi, C. Nano Lett. 2012, 12, 3925-3930. doi:10.1021/nl300901a

43. Das, A.; Pisana, S.; Chakraborty, B.; Piscanec, S.; Saha, S. K.; Waghmare, U. V.; Novoselov, K. S.; Krishnamurthy, H. R.; Geim, A. K.; Ferrari, A. C.; Sood, A. K. Nat. Nanotechnol. 2008, 3, 210-215. doi:10.1038/nnano.2008.67

44. Casiraghi, C.; Pisana, S.; Novoselov, K. S.; Geim, A. K.; Ferrari, A. C. Appl. Phys. Lett. 2007, 91, 233108. doi:10.1063/1.2818692

45. Liu, L.; Ryu, S.; Tomasik, M. R.; Stolyarova, E.; Jung, N.; Hybertsen, M. S.; Steigerwald, M. L.; Brus, L. E.; Flynn, G. W. Nano Lett. 2008, 8, 1965-1970. doi:10.1021/nl0808684

46. Li, X.; Wang, H.; Robinson, J. T.; Sanchez, H.; Diankov, G.; Dai, H. J. Am. Chem. Soc. 2009, 131, 15939-15944. doi:10.1021/ja907098f

47. Peng, H.; Mo, Z.; Liao, S.; Liang, H.; Yang, L.; Luo, F.; Song, H.; Zhong, Y.; Zhang, B. Sci. Rep. 2013, 3, 1765. doi:10.1038/srep01765

48. Choudhury, D.; Das, B.; Sarma, D. D.; Rao, C. N. R. Chem. Phys. Lett. 2010, 497, 66-69. doi:10.1016/j.cplett.2010.07.089

49. Kundu, S.; Nagaiah, T. C.; Xia, W.; Wang, Y.; Van Dommele, S.; Bitter, J. H.; Santa, M.; Grundmeier, G.; Bron, M.; Schuhmann, W.; Muhler, M. J. Phys. Chem. C 2009, 113, 14302-14310. doi:10.1021/jp811320d

50. Matter, P. H.; Zhang, L.; Ozkan, U. S. J. Catal. 2006, 239, 83-96. doi:10.1016/j.jcat.2006.01.022 
51. Shao, Y.; Zhang, S.; Engelhard, M. H.; Li, G.; Shao, G.; Wang, Y.; Liu, J.; Aksay, I. A.; Lin, Y. J. Mater. Chem. 2010, 20, 7491-7496. doi:10.1039/c0jm00782j

52. Nolan, H.; Mendoza-Sanchez, B.; Ashok Kumar, N.; McEvoy, N.; O'Brien, S.; Nicolosi, V.; Duesberg, G. S. Phys. Chem. Chem. Phys. 2014, 16, 2280-2284. doi:10.1039/c3cp54877e

53. Lv, R.; Li, Q.; Botello-Méndez, A. R.; Hayashi, T.; Wang, B.; Berkdemir, A.; Hao, Q.; Elías, A. L.; Cruz-Silva, R.; Gutiérrez, H. R.; Kim, Y. A.; Muramatsu, H.; Zhu, J.; Endo, M.; Terrones, H.; Charlier, J.-C.; Pan, M.; Terrones, M. Sci. Rep. 2012, 2, 586. doi:10.1038/srep00586

54. Dressel, M.; Grüner, G. Electrodynamics of Solids: Optical Properties of Electrons in Matter; Cambridge University Press: Cambridge, U.K., 2002. doi:10.1017/CBO9780511606168

55. Nemes-Incze, P.; Osváth, Z.; Kamarás, K.; Biró, L. P. Carbon 2008, 46, 1435-1442. doi:10.1016/j.carbon.2008.06.022

56. Faggio, G.; Capasso, A.; Malara, A.; Leoni, E.; Nigro, M. A.; Santangelo, S.; Messina, G.; Dikonimos, T.; Buonocore, F.; Lisi, N. Fast growth of polycrystalline graphene by chemical vapor deposition of ethanol on copper. Nanotechnology Materials and Devices Conference (NMDC), 2014 IEEE 9th; 2014; pp 69-72. doi:10.1109/NMDC.2014.6997424

57. Vlassiouk, I.; Regmi, M.; Fulvio, P.; Dai, S.; Datskos, P.; Eres, G.; Smirnov, S. ACS Nano 2011, 5, 6069-6076. doi:10.1021/nn201978y

\section{License and Terms}

This is an Open Access article under the terms of the Creative Commons Attribution License (http://creativecommons.org/licenses/by/2.0), which permits unrestricted use, distribution, and reproduction in any medium, provided the original work is properly cited.

The license is subject to the Beilstein Journal of Nanotechnology terms and conditions: (http://www.beilstein-journals.org/bjnano)

The definitive version of this article is the electronic one which can be found at: doi:10.3762/bjnano.6.206 